\title{
Quality of life, depression, anxiety and suicidal ideation among men who inject drugs in Delhi, India
}

Gregory Armstrong ${ }^{1 *}$, Amenla Nuken ${ }^{1}$, Luke Samson ${ }^{2}$, Shalini Singh ${ }^{2}$, Anthony F Jorm $^{3}$ and Michelle Kermode ${ }^{1}$

\begin{abstract}
Background: Mental disorders such as depression, anxiety and suicide represent an important public health problem in India. Elsewhere in the world a high prevalence of symptoms of common mental disorders have been found among people who inject drugs (PWID). Research in India has largely overlooked symptoms of common mental disorders among this high risk group. This paper reports on the results of a survey examining quality of life, depression, anxiety and suicidal ideation among adult males who inject drugs living in Delhi.

Methods: Participants $(n=420)$ were recruited from needle and syringe programs using time location sampling and were interviewed using an interviewer-administered questionnaire. Self-report symptom scales were used to measure the severity of symptoms of depression (PHQ-9) and anxiety (GAD-2) within the preceding 2 weeks. We assessed the presence of suicidal thoughts and attempts within the past 12 months.

Results: The mean length of injecting career was 20.9 years indicating a sample of chronic injecting drug users, of whom only one-third (38\%) were born in Delhi. The level of illiteracy was very high (62\%), and just 2\% had completed class 12. Scavenging / rag picking was the main form of income for $48 \%$, and many were homeless (69\%). One-third (33\%) had been beaten up at least twice during the preceding 6 months, and many either never $(45 \%)$ or rarely $(27 \%)$ attended family events. We found a high prevalence of depressive $(84 \%$, cut-off $\geq 10)$ and anxiety $(71 \%$, cut-off score of $\geq 3)$ symptoms. Fifty-three percent thought about killing themselves in the past 12 months, and 36\% had attempted to kill themselves.

Conclusions: Our findings revealed a socially excluded population of PWID in Delhi who have minimal education and are often homeless, leaving them vulnerable to physical violence, poverty, poor health, imprisonment and disconnection from family. The high prevalence of psychological distress found in this study has implications for programmes seeking to engage, treat and rehabilitate PWID in India.
\end{abstract}

\section{Background}

Mental disorders are one of the leading contributors to the global burden of disease in both high and low income countries [1]. Common mental disorders such as depression and anxiety are frequently comorbid with other health and psychosocial problems and are among the most important causes of morbidity [1-3]. Mental health remains a low priority in most low and middle income countries and unmet needs for treatment are pervasive [4-6].

\footnotetext{
* Correspondence: g.armstrong@unimelb.edu.au

${ }^{1}$ Nossal Institute for Global Health, University of Melbourne, Victoria, Australia Full list of author information is available at the end of the article
}

Mental disorders constitute a major public health problem in India [7-9]. Epidemiological studies have reported prevalence rates for psychiatric disorders varying from 9.5 to $370 / 1000$ population, with prevalence highest among marginalised populations and those most disadvantaged by the phenomenon of rapid economic growth and urbanization, such as urban slum dwellers [10]. High rates of suicide have been documented in India [11-14]. The real frequency of attempted suicide is thought to be under-reported due to a poor reporting system and the social taboos and legal ramifications (attempted suicide is a punishable offence under Section 309 of the Indian Penal Code) connected to suicide $[12,15]$.

\section{Biomed Central}


Previous research has documented the co-occurrence of mental disorders and illicit substance use [16,17]. The association can be explained in different ways. Psychiatric disturbance can occur before or after the commencement of illicit substance use: people may use illicit substances to manage their psychiatric symptoms; the pharmacological properties of illicit substances such as amphetamines can induce psychiatric symptoms; the symptoms of withdrawal connected with drug addiction can mimic those of common mental disorders; and, the psychosocial stressors connected with life for people who use illicit substances create distress and can have a detrimental effect on mental health [18]. The precise origin of psychiatric symptoms may not be so critical given that comorbid psychiatric symptoms in substance users are connected with a poor long-term prognosis regardless of whether these symptoms were independent of the substance use or were a consequence of it [19-21].

A high prevalence of symptoms of depression, anxiety and suicidal ideation has been found among people who inject drugs (PWID) in high-income country settings using different diagnostic methods, instruments, cut-off values, and population samples [22-26]. Few studies have examined the phenomenon of symptoms of common mental disorders among PWID in Asian country settings, and those few studies that have been undertaken have found similarly high levels of psychiatric symptomatology [27-30]. To the best of our knowledge, there has been only one community-based study among PWID in India that measured the prevalence of suicidal ideation and that was in the context of a study focused on human rights violations [31]; there have been no studies using community-based samples that measured depression or anxiety symptoms.

This paper reports on the results of a cross-sectional survey examining quality of life, depression and anxiety symptoms, and suicidal ideation among a communitybased sample of adult males who inject drugs living in Delhi. The populations of PWID in Delhi, estimated to be at around 35,000 [32] are from various walks of life, but most are substantially alienated and impoverished and live at the margins of society [33]. Our study of symptoms of common mental health problems among PWID in Delhi will have implications for public health programmes targeting this population.

The research questions framing our study were: (1) what are the quality of life and socio-economic characteristics of this population of PWID?; (2) what is the prevalence of symptoms of depression and anxiety and suicidal ideation?; (3) what psychosocial factors are associated with symptoms of depression, anxiety and suicidal ideation?; and, (4) is there an association between risky injecting and sexual practices and symptoms of depression, anxiety and suicidal ideation? This paper will only report on the first and second research questions to allow for a full discussion of the characteristics of this population. The other objectives will be reported in depth elsewhere.

\section{Methods}

\section{Study design}

In April and May of 2012, a cross-sectional survey was undertaken among PWID in Delhi using a structured questionnaire that was interviewer-administered. Ethics approval was provided in Australia by the Human Research Ethics Committee at The University of Melbourne (HREC 1137025). Local ethics approval was provided in India by the Institutional Review Board (IRB) at Sharan, The Society for Service to Urban Poverty. Sharan is an NGO that provides services to injecting drug users in New Delhi and is the partner NGO on this study.

\section{Participants}

Eligible participants were those who were 18 years of age or older, had injected drugs at least once in the past month, were not currently enrolled in opioid substitution therapy (i.e. buprenorphine), and had given their informed oral consent to participate in the study. A consent form and plain language statement were orally communicated to potential participants, as literacy was limited for many participants. Consent was obtained orally after reading out the consent form. Participation in the study was voluntary and anonymous - no names or individually identifying information were recorded at any stage. Participants were provided with a small meal (e.g. chai and samosa) for their time in participating in the study. Participants were free to withdraw from the study during the questionnaire without losing access to the meal.

Participants were sampled from three needle and syringe programmes (NSPs) in Delhi, each located in a distinctly different geographical area so that the sample was drawn from a diverse range of PWID from across Delhi; 1) Yamuna Bazar, 2) Nabi Karim, and 3) Jahangirpuri. Yamuna Bazar is located on the bank of the Yamuna River in central Delhi and is the base for a large proportion of the capital's homeless and PWID. Jahangirpuri is a slum resettlement colony on the outskirts of metropolitan Delhi. The NSP at Nabi Karim is located in an urban ghetto in the Muslim quarter adjacent to New Delhi Railway Station.

According to current data presented in the recent National AIDS Control Organisation (NACO) Annual Report 2011-2012 [34], it is estimated that $80 \%$ of the officially mapped IDU population usually obtain their needles from NSP targeted interventions depending on the location.

\section{Sampling method}

The data were collected using Time Location Sampling (TLS), a recognized method for obtaining a probability- 
based sample from hidden populations [35-38]. TLS sampling involves building a sampling frame from a list of location and time combinations based upon the locations and times where you would expect to find members of the target population. The NSPs were mapped in terms of their operating hours and a list was constructed based on a combination of the locations (i.e. NSPs) and blocks of time (e.g. 3 hour blocks) during which the NSP would be operating. Combinations of location and time, known as sampling events, were then randomly selected from the list to populate a sampling calendar. The random number generator in Excel was used to randomly select sampling events for each date on the sampling calendar. The sampling calendar detailed the location and time that the data collection team would attend on a given date. Sampling was conducted during April and May 2012 until the desired sample size was achieved.

Based on programme data, it was anticipated that there were twice as many PWID using the NSP in the Yamuna Bazar location in comparison to the other two locations. The selection of sampling events for the sampling calendar was weighted with probability proportionate to size, so that approximately half the sampling events would be drawn from the Yamuna Bazar location and the remaining half would be evenly split between Jehangipuri and Nabi Karim.

The data collection team consisted of one field supervisor, one enumerator and four interviewers who were responsible for recruiting and interviewing participants. During sampling events, the enumerator would use a "counter" to count every male who used the NSP to obtain new needles/syringes. Interviewers were directed by the enumerator to approach potential participants immediately after they had obtained new needles / syringes from the NSP. Not all people using the NSP during a sampling event could be approached to participate given there was a limited number of interviewers. Additionally, there would be more people attending the NSPs during some sampling events than others, thus creating a scenario of unequal probability of selection for participants across sampling events. The enumerator counted all people actually interviewed during each sampling event in addition to counting those who had used the NSP to enable the construction of selection probability weights as discussed in the data analysis section below. Additionally, the enumerator collected data on the number of people who were approached yet declined to participate and the number of participants who terminated the interview early.

\section{Data collection and measurement}

The questionnaire was interviewer-administered to maximize the quality of the data collected. The questionnaire had five domains: 1) background information including socio-demographics, 2) drug use practices, 3) sexual behaviour, 4) quality of life, and 5) symptoms of depression, anxiety and suicidal ideation. It was anticipated that many of the participants would have never received any schooling. As a result, the questionnaire was kept as brief and simple as possible and it took approximately 30 minutes to complete. The questionnaire was translated into Hindi, back-translated into English and then piloted in the field to ensure equivalence and appropriateness of the questions and scales. Local research assistants were used for the data collection phase, all of whom had previously been involved in administering questionnaires with PWID. The research assistants were trained in using the questionnaire and ethical research conduct and were closely supervised by an experienced local research officer.

\section{Demographics, injecting and sexual practices}

Questions regarding demographics, drug use and sexual behaviours (predominantly condom use with various partners) were adapted from previous research [39] among injecting drug users in New Delhi and from a sub-set of questions adapted from the Integrated Biological and Behavioural Assessment (IBBA) survey previously undertaken among injecting drug users in three states of India, in both 2006 and 2009 [40].

\section{Quality of life}

Four generic questions relating to quality of life were asked, covering four different aspects of quality of life. The questions were adapted from themes contained within the WHOQoL scale [41] and the IDUQoL scale $[42,43]$, neither of which proved feasible to use in this study during pilot testing due to the length of these instruments and challenges in translating concepts. The adapted questions were pertaining to: 1) hope for the future, 2) feeling safe in daily life (i.e. from crime and violence), 3) perception of health, and 4) relationship with family. Additional socio-economic variables that are also indicators of quality of life included: literacy, level of education, income, source of income, housing, history of imprisonment, experiences of being beaten and inclusion in family events.

\section{Symptoms of depression, anxiety and suicidal ideation}

Symptoms of depression were measured using the $\mathrm{Pa}$ tient Health Questionnaire (PHQ-9), a nine-item screening tool based on criteria for depressive disorders in the Diagnostic and Statistical Manual of Mental Disorders (DSM-IV) $[44,45]$. The PHQ-9 has well established criterion, construct and external validity $[46,47]$. The PHQ9 asks participants whether they have been bothered with nine symptoms in the past two weeks, with response options on a four-category Likert scale; not at all 
(0), several days (1), more than half the days (2), nearly every day (3). The PHQ-9 is relatively short to administer with scores ranging from 0 to 27. Scores of 5, 10, 15 and 20 represent thresholds marking the lower limits of mild, moderate, moderately severe and severe depression.

The conventional cut-off is $\geq 10$, yielding a sensitivity of $88 \%$ and a specificity of $88 \%$ for major depression [45]. The PHQ has previously been translated into Hindi, validated for use among South Asian populations and used in previous studies measuring the prevalence of depressive symptoms among various communities in India [48-52]. It has been recommended as a measure for symptoms of depression among PWID in NSP settings [53].

Symptoms of anxiety were measured using the Generalised Anxiety Disorder (GAD-2) scale, a two-item ultrabrief screening tool that follows the same format and response options as the PHQ-9 [54]. Scores on the GAD-2 range from 0 to 7 with a score of $\geq 3$ representing the optimum cut-point for screening for anxiety disorders. The GAD-2 has high sensitivity (86\%) and specificity (83\%) for detecting generalised anxiety disorder and high specificity for panic disorder (81\%), social anxiety disorder (81\%) and post-traumatic stress disorder (81\%) [54]. The GAD-2 has previously been translated into Hindi.

Suicidal ideation was captured using three questions adapted from the Suicide Behaviours Questionnaire (SBQ) [55]. Questions were asked pertaining to: 1) thoughts of suicide during the previous 12 months, 2) the frequency of such thoughts, and 3) whether or not a plan to act on these thoughts had been made. Additionally, participants were asked whether they had attempted suicide during the past 12 months.

\section{Sample size}

With an assumed prevalence of psychological distress of $50 \%$ (the most conservative assumption for the sample size calculation) and a 95\% confidence interval with a $5.5 \%$ margin of error, it was calculated that a sample size of 312 PWID would be required. TLS sampling is similar to cluster sampling, as randomly selected 'blocks of time and space' are potentially clusters of homogeneity. The required sample size was increased to 420 after adjusting for a design effect of 1.25 .

\section{Data analysis}

Data were entered into SPSS version 20 and crosschecking was undertaken among $10 \%$ of questionnaires to ensure there were no systematic errors when entering the data. Preliminary tables were generated for each variable to check for invalid entries. Data were analysed using Stata version 10. Survey commands in Stata were used to account for the TLS sampling design, specifically the effect of clustering within sampling events and the probability that a person was sampled $[36,56]$. Participants recruited at each sampling event (combination of time and location) were treated as a cluster and standard errors for variables were adjusted for intra-cluster correlation. Sampling events at different times but at the same location were treated as separate clusters. The number of attendees at a sampling location during each sampling event (i.e. enumeration count) was used as the basis upon which to construct selection probability weights. In brief, the first step was to calculate the proportion that each event represented of the total enumeration count for the entire study. The second step was to calculate the proportion of the total number of interviews that each event represented for the entire study. Finally, the result from step 1 was divided by the result from step 2 to generate a weight that represents the ratio of the number of persons enrolled into the study relative to the number of persons available to sample from at each sampling event. Thus, more weight was given to participants recruited at highly-attended sampling events.

Descriptive analysis produced adjusted proportions and means with their respective 95\% confidence intervals (C.I.). The range and median were used to provide important information as to the distribution of the continuous depressive and anxiety symptom measures. Because these statistics could not be generated using survey commands in Stata, due to the limited options available in these commands, they were generated without adjustment for the sampling design.

\section{Results}

Recruitment

There were 420 PWID recruited into the study: 220 (52\%) from Yamuna Bazar, 100 (24\%) from Nabi Karim and 100 (24\%) from Jehangipuri. During recruitment there were 173 PWID who were approached but declined to participate; if we take a conservative assumption that all 173 met the inclusion criteria, this would indicate a response rate of $71 \%(420 \div(420+173))$. There were no occasions where a participant terminated the interview before it was completed.

\section{Demographics and substance use}

Table 1 displays the demographic characteristics and substance use practices of PWID in this study setting. The mean age was 36.7 (95\% C.I. 35.5-37.9). Only one in nine (11\%) was below the age of 25 and one-quarter were aged 45 or older (26\%). Many PWID were born outside of New Delhi, with just over one-third (38\%) being born there. Just over half (53\%) had never been married and nearly one-quarter were either divorced / separated (16\%) or widowed (7\%); more than half (60\%) had no children. 
Table 1 Demographics and substance use $(n=420)$

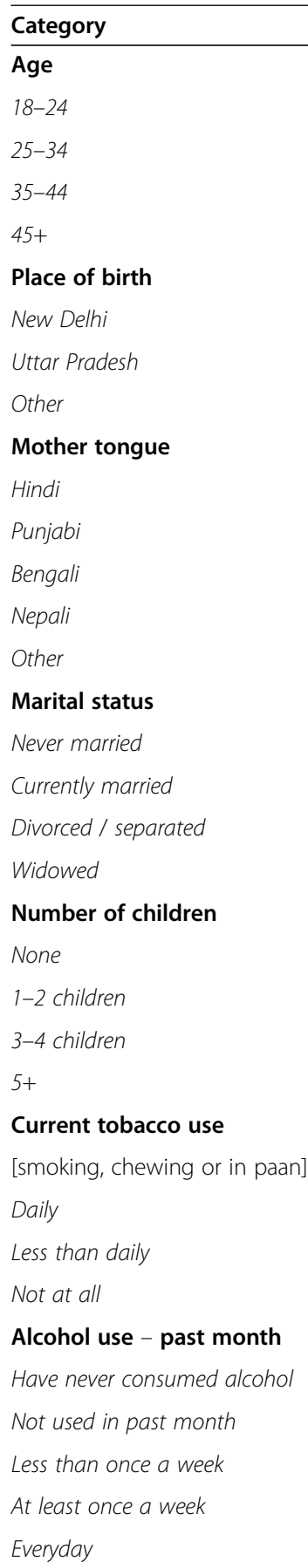

Age at first injection

$\leq 13$

$14-16$

$17-19$

$20+$

Drugs used in the last 3 months ${ }^{a}$

Pheniramine maleate

Buprenorphine
$\%$ (95 \% C.I.)

$11.3(7.1-15.6)$

$34.4(28.2-40.6)$

$28.7(23.7-33.6)$

$25.6(19.8-31.4)$

$38.3(26.7-50.0)$

$27.9(22.2-33.6)$

$33.7(25.2-42.3)$

$74.4(67.5-81.3)$

$6.5(3.6-9.5)$

$4.6(1.95-7.3)$

$4.3(2.1-6.5)$

$10.2(6.0-14.4)$

$53.3(46.4-60.1)$

$24.6(17.8-31.4)$

$15.5(12.0-19.0)$

$6.6(3.0-10.2)$

$60.3(53.7-66.9)$

$26.4(22.0-30.9)$

$10.4(6.3-14.5)$

$2.9(0.6-5.2)$

$93.2(90.1-96.2)$

$4.9(2.3-7.6)$

$1.9(0.5-3.3)$

$21.1(14.4-27.7)$

$43.4(36.1-50.7)$

$9.5(6.9-12.1)$

$19.1(14.4-23.7)$

$7.0(3.3-10.7)$

$34.1(29.1-39.0)$

$26.2(21.6-30.8)$

$18.3(13.7-22.9)$

$21.5(15.9-27.1)$

$99.0(98.1-100.0)$

$97.4(95.4-99.3)$
Table 1 Demographics and substance use $(n=420)$ (Continued)

\begin{tabular}{ll}
\hline Heroin & $76.6(69.9-83.3)$ \\
Marijuana & $73.0(63.4-82.7)$ \\
Diazepam & $53.0(44.8-61.1)$ \\
Promethazine & $42.3(35.6-48.9)$ \\
Spasmoproxyvon & $26.5(19.1-33.9)$ \\
Pentazocine / morphine & $25.1(19.6-30.6)$ \\
Other & $22.2(17.1-27.4)$
\end{tabular}

Main drug injected in last 3 months ${ }^{b}$

Buprenorphine base

$76.9(69.7-84.1)$

Heroin base

$18.0(11.6-24.3)$

Other

$5.2(1.7-8.6)$

Number of times injected during past week

$\leq 7$

$14.4(10.4-18.3)$

8-14

$28.7(23.0-34.3)$

$15-21$

$36.4(30.9-42.0)$

$22+$

$20.5(15.5-25.5)$

a Buprenorphine, heroin, morphine, pentazocine (common brand name is Fortwin) and Spasmoproxyvon are synthetic opioid analgesics. Spasmoproxyvon is the brand name for a compound drug containing dextropropoxyphene, dicyclomine hydrochloride and paracetamol. Pheniramine maleate (common brand name is Avil) and promethazine (common brand name is Phenergan) are antihistamines.

${ }^{b}$ Both buprenorphine and heroin are commonly injected in a cocktail combination with a liquid antihistamine and often diazepam as well.

Tobacco was consumed daily for the majority of these PWID (93\%). Few (7\%) consumed alcohol daily. The mean age of first injection was 15.8 (95\% C.I. 15.3-16.3) and one-third (34\%) had first injected at the age of 13 or younger. The mean length of injecting career was 20.9 years (95\% C.I. 19.8-22.0). The most commonly used opioids in the last three months were buprenorphine (97\%), heroin (77\%), Spasmoproxyvon (27\%) and pentazocine / morphine (25\%). Buprenorphine, Spasmoproxyvon and pentazocine / morphine are synthetic opioid analgesics commonly found in chemist shops. Spasmoproxyvon is the brand name for a compound drug containing dextropropoxyphene, dicyclomine hydrochloride and paracetamol. Other commonly used drugs were marijuana (73\%), diazepam (53\%) and antihistamines (pheniramine maleate / Avil 99\%, promethazine / Phenergan 42\%). The main drug injected in the last three months was typically buprenorphine $(77 \%)$ or heroin $(18 \%)$, both of which were commonly injected in a cocktail with a liquid antihistamine and often diazepam as well. Few (14\%) PWID were injecting only once a day or less.

Quality of life and defining socio-economic characteristics Table 2 presents the quality of life and socio-economic characteristics, showing an extremely impoverished and marginalised community of PWID. Just one-fifth of 
PWID felt very hopeful for their future (21\%) or felt very safe in their daily life from violence, crime and harassment (18\%); over one-quarter reported feeling not at all safe $(28 \%)$. Few rated their personal health as either very good $(1 \%)$ or good (11\%). Similarly, few rated their relationship to family as either very good (3\%) or good (14\%) and the majority reported that they either rarely (27\%) or never $(45 \%)$ attend family events.

The level of illiteracy was very high (62\%) and just 2\% had completed 12 years of primary and secondary education. On average, PWID in this community live off a mean of 193.5 rupees per day (95\% C.I. 181.1-206.0), roughly \$US3.50 and approximately half had a daily income of $\leq 100$ rupees (22\%) or $101-150$ rupees $(27 \%)$. Scavenging / rag picking was the main form of income for $48 \%$ of PWID and just under one-third did either unskilled manual work (19\%) or skilled manual work (11\%). A small group of PWID primarily generated their income from either crime (6\%) or begging (2\%).

There was a very high proportion of PWID who were homeless (69\%) and several others mostly slept in insecure housing including rented rooms (6\%) and other temporary housing (4\%). Seventy percent had a history of imprisonment. Experiences of physical violence were common: $33 \%$ had been beaten up at least twice during the preceding six months and $11 \%$ had been beaten up four or more times.

\section{Depression, anxiety and suicidal ideation}

Table 3 presents the prevalence of recent symptoms of depression and anxiety and the 12-month prevalence of suicidal ideation. The PHQ-9 scale had satisfactory internal consistency (Cronbach's alpha coefficient $=0.73$ ). The mean PHQ-9 score was 14.7 out of a total possible score of 27, with a range of 1 to 25 and a median of 15 . The prevalence of moderate or worse symptoms of depression (cut-off $\geq 10$ ) was $84 \%$ and the prevalence of moderately severe to severe symptoms of depression (cut-off $\geq 15$ ) was $54 \%$.

Among the nine items on the PHQ-9, the highest average score was for the item "feeling bad about yourself - or that you are a failure or have let yourself or your family down"; the mean was 2.2 (95\% C.I. 2.1-2.3). The proportion of participants who received the maximum score of 3 (i.e. had this symptom nearly every day in the last two weeks) for this item was 51\% (95\% C.I. 44\%-58\%).

The mean GAD-2 score was 3.4 out of a total possible score of 6 , with a range of 0 to 6 and a median of 4. Seventy-one percent qualified as having anxiety symptomatology (cut-off score of $\geq 3$ ). There was a small group (10\%, 95\% C.I. 6\%-14\%) of PWID who displayed no recent (i.e. past two weeks) symptoms of either depression or anxiety.
Suicidal ideation during the past 12 months was common. Fifty-three percent thought about killing themselves and almost one-quarter either often (15\%) or very often (7\%) thought about killing themselves. A substantial proportion reported to have actually attempted to kill themselves (36\%) in the past 12 months.

\section{Discussion}

The findings from this study profile an impoverished, vulnerable and isolated population of men who inject drugs and whose lives are shaped by a significant level of psychosocial distress. The average age of participants was in the mid-30s with few aged below 25 and most had commenced their injecting careers during adolescence, indicative of a population of PWID who belong to the more chronic end of the addiction spectrum. The prevalence of symptoms of depression and anxiety was very high and suicidal thoughts and acts were disconcertingly common.

\section{Low quality of life and socio-economic status}

More than half the participants were born outside of Delhi, suggesting many of these men were part of the phenomenon of large-scale migration into the city whether as adults or children. Migration into Delhi has fuelled a population growth rate of between 4-5\% per year between 1951 and 2001 [57], making Delhi the home to 16.7 million people [58] and a megacity that ranks among the largest on the planet.

In our study, the quality of life and socio-economic indicators reveal a socially excluded population of PWID in Delhi who have minimal education and are often homeless, leaving them vulnerable to physical violence, poverty, poor health and imprisonment. These men are clearly excluded from the rapid social and economic progress around them.

The social exclusion extends to family relationships, the core of the social fabric in India [59], with many among this population never $(45 \%)$ or rarely $(27 \%)$ attending family events. Aside from the potential for breakdown in family relationships in connection with migration, there are clearly other explanations connected to drug addiction and family dynamics. The heightened level of stigma, shame and alienation associated with injecting drug use in a conservative Indian society would threaten the integrity of a family and deepen the fracturing of relationships [60]. To the best of our knowledge there is minimal research in India, if any, examining drug users' perspectives regarding their relationships with family and the potential for meaningful engagement of family in drug treatment linked to harm reduction. Given the pivotal role of family in Indian society, there would be value in a more thorough examination of both 
Table 2 Quality of life and socio-economic indicators ( $n=420)$

Category
Feel hopeful for your fut
Very hopeful
Somewhat hopeful
Not at all hopeful
Feel safe in your daily life
[safe from violence, crime and
Very safe
Somewhat safe
Not at all safe
Rating of personal health
Very good
Good
Average
Poor
Very poor
Relationship with family
Very good
Good
Average
Poor
Very poor

Included in family events

Always

Some or most of the time

Rarely

Never

Literacy

Literate

Illiterate

Years of primary and secondary education completed

Never attended school

Completed between 1-4 years

Completed between 5-11 years

Completed 12 years

Daily income (rupees) ${ }^{a}$

$\leq 100$ rupees

101-150 rupees

151-200 rupees

201-250 rupees

$251+$ rupees

Main source of income

Skilled manual work

Unskilled manual work
$21.9(16.7-27.1)$

$\%$ (95\% C.I.)

$21.1(15.5-26.7)$

$60.0(55.5-64.4)$

$19.0(14.4-23.5)$

$17.7(13.0-22.4)$

$54.2(47.6-60.7)$

$0.7(0.0-1.4)$

$10.9(7.3-14.6)$

$45.9(40.7-51.2)$

$26.8(22.1-31.4)$

$15.6(10.3-20.9)$

$3.0(1.1-5.0)$
$13.5(9.8-17.2)$
$43.0(37.7-48.4)$
$21.3(15.5-27.1)$
$19.2(13.0-25.3)$

$16.4(9.6-23.2)$

$11.1(7.8-14.3)$

$27.1(22.9-31.3)$

$45.4(38.4-52.5)$

$37.8(56.7-67.6)$

$62.2(56.7-67.6)$

$38.0(32.7-43.3)$

$28.0(22.9-33.2)$

$32.1(27.4-36.8)$

$1.8(0.6-3.1)$

$26.8(21.7-32.0)$

24.3 (19.8-28.8)

$11.9(7.8-16.0)$

$15.1(10.7-19.6)$

10.9 (6.3-15.5)

$18.7(11.7-25.8)$
$28.2(21.8-34.6)$
Table 2 Quality of life and socio-economic indicators ( $n=420)$ (Continued)

\begin{tabular}{lr}
\hline Scavenging (e.g. rag picking) & 47.8 (37.5-58.2) \\
Trading / vending & $1.8(0.5-3.2)$ \\
Crime (e.g. pick pocketing, selling drugs, etc.) & $5.7(2.4-9.0)$ \\
Begging & $1.7(0.1-3.3)$ \\
No source of income & $11.1(7.1-15.1)$ \\
Other & $2.2(0.1-3.9)$
\end{tabular}

Place where slept most in past 3 months

Homeless

$68.8(57.4-80.3)$

House / flat of relative or friend

$16.0(8.6-23.4)$

Own house or flat

$5.9(1.6-10.2)$

Rented room (hotel or rooming house)

$5.7(3.1-8.2)$

Other temporary housing

$3.6(1.8-5.3)$

Ever been imprisoned

No

$30.4(27.2-33.5)$

Yes

$69.6(66.5-72.8)$

Number of times beaten up in the past 6 months

0

$50.7(44.5-57.0)$

1

$15.7(10.6-20.9)$

2

$13.2(9.5-16.9)$

$9.3(6.4-12.1)$

3

$11.0(8.4-13.5)$

a 1.00 USD $=54.25$ rupees [as of 9th May 2013].

the drug users' and family-members' perspectives on drug dependence and family relationships.

A high prevalence of common mental health symptoms There was a high prevalence of symptoms of depression and anxiety among this community-based population of men who inject drugs. In our study, 84\% (PHQ-9 $\geq 10$ ) had symptoms of depression, 54\% (PHQ-9 $\geq 15$ ) had moderately severe or severe symptoms of depression and $71 \%$ (GAD-2 23 ) had symptoms of anxiety. The most common symptom of depression was feelings of worthlessness and self-blame which is not very surprising given the highly stigmatised nature of injecting drug use, the disconnection with family and the deprived socio-economic circumstances for many among this population, but is in contrast to the findings of a population-based survey of depression in Chennai that also used the PHQ and reported depressed mood as the most common symptom [51].

These results are somewhat comparable to studies conducted in high-income countries among PWIDs using self-report symptoms scales, despite variation in study settings and the particular scale used. Lemstra et al. [22] used the CES-D (cut-offs $\geq 16, \geq 23$ ) among 
Table 3 Prevalence of recent symptoms of depression and anxiety, and 12-month prevalence of suicidal ideation $(n=420)$

Category
Depression and anxiety scales - averages
PHQ-9 score: average
GAD-2 score: average
Depression and anxiety scales - cut points
PHQ-9 score: $\geq 10$
PHQ-9 score: $\geq 15$
PHQ-9 score: $\geq 20$
GAD-2 score: $\geq 3$

\section{Suicidal ideation}

Have you thought about killing yourself in the past 12 months?

No

Yes

How often have you thought about killing yourself in the past 12 months?

Never

Rarely (1 time)

Sometimes (2 times)

Often (3-4 times)

Very often (5 or more times)

Have you ever made a plan to kill yourself in the past 12 months?

No

Yes

Have you ever attempted to kill yourself in the past 12 months?

No

Yes

Note: PHQ-9 scores of $\geq 10, \geq 15$ and $\geq 20$ represent cut points for moderate, moderately severe and severe depression symptomology. A GAD-2 score of $\geq 3$ represents the optimum cut point when screening for anxiety.

PWID in the Saskatoon Health Region of Canada and found a point prevalence of depressive symptomatology of $81 \%$, with $58 \%$ having more severe depressive symptoms. Perdue et al. [23] also used the CES-D (cut-off $\geq 23$ ) among PWID in Seattle (USA) and similarly found that $47 \%$ had more severe depressive symptoms. Brienza et al. [24] used the Structured Clinical Interview for DSM-III-R (SCID) and found a point prevalence of major depression over the last 6 months of $54 \%$ among PWID in Rhode Island (USA) attending needle syringe exchange programmes and $42 \%$ among PWID attending methadone maintenance treatment. Reyes et al. [25] used the Beck Anxiety Inventory (moderate levels 1625 , severe levels $\geq 26$ ) among PWID in Puerto Rico; over half of participants were found to have either moderate (19\%) or severe (37\%) levels of anxiety.
Similarly high prevalence rates have been found in other studies conducted in the Asian region. Gu et al. [28] used the Depression Anxiety and Stress Scale (DASS) among a snowball sample of females who inject drugs in Dazhou city (Sichuan Province, China) and found a high percentage of participants reported depressive symptoms (75\% to 92\%). Liao et al. [29] used the Zung Self-Rating Anxiety Scale (SAS) and the Zung SelfRating Depression Scale (SDS) among a sample of heroin-dependent patients in a treatment research clinic in Changsha city (Hunan Province, China) and found a high prevalence of both high anxiety (53\%) and depression $(43 \%)$ symptoms.

Our study revealed a disconcertingly high prevalence of suicidal ideation. We found that $53 \%$ had thought about killing themselves in the past 12 months and 34\% had made a plan to kill themselves. This result is the same as that found by Sarin et al. [31] who measured suicidal ideation among PWID in Delhi whilst conducting a study focused on human rights abuses: $57 \%$ had thought of taking their own life in the past six months and $42 \%$ reported having made a specific plan about how they would take their own life. High rates of suicidal ideation have been found among PWID elsewhere: Havens et al. [26] surveyed a sample of PWID in Maryland (USA) and found that $27 \%$ had thought about killing themselves in the past 6 months.

Our study also found that many (36\%) men who inject drugs in Delhi had moved beyond thinking about killing themselves to actually attempting to kill themselves in the past 12 months. Suicide is a real option for these men, with at least one means readily available in the form of a drug overdose. Chen et al. [30] also found that suicide attempts were common among heroin users in Taiwan; they surveyed entrants to methadone maintenance treatment and found that $10.9 \%$ had attempted suicide in the previous month.

\section{Implications for programmes seeking to integrate a focus} on mental health

The high prevalence of psychological distress found in this study has implications for programmes seeking to engage, treat and rehabilitate PWID in India. Two broad approaches appear to be worth further consideration, although both face substantial challenges. One approach to integrating mental health into services for PWID would be to adopt a conventional psychiatric biomedical model based around the use of screening tools and referral mechanisms complimented by the development of mental health literacy $[61,62]$ and mental health first aid initiatives $[63,64]$ for programmes providing services to PWID. In an ideal world the development of locally appropriate and easily administered and interpreted mental health screening tools could provide a quick method for 
programmes to identify PWID with severe symptoms of common mental health problems. Screening tools could theoretically be complemented by the development of pathways of referral for mental health assessment at the primary health care level or, where appropriate, through psychiatric institutions.

However, there is a question mark over whether conventional screening and treatment approaches would be effective for people who live in such adverse circumstances. Separating human distress from a diagnosis of depression or anxiety is difficult [65]. Furthermore, given that the unmet need for mental health care in India is very high [4], it is unlikely that this disenfranchised population group will be able to reliably access psychiatric or psychological treatment when needed without strong advocacy and positive relationships with treatment providers. The sheer number of new referrals that may be generated from the regular use of screening tools among this population group might overwhelm already stretched mental health services. Additionally, there may be obstacles to persuading PWID to attend assessments and treatments and there may be financial barriers related to the costs of assessment and treatment.

Whilst severe depression and anxiety may require psychiatric treatment, those with milder to moderate symptoms could be better served by the adoption of a broader public health approach that targets the population rather than the individual [66]. The concept of mental health promotion is a possible alternative to the conventional psychiatric biomedical model. A mental health promotion approach would involve addressing the social determinants of mental health and well-being, those being social inclusion, freedom from discrimination and violence and economic participation [67]. Structural interventions seeking to improve access to social/group activities and addressing unemployment and housing insecurity could be critical strategies for addressing mental health among this population of men who experience multiple levels of deprivation.

\section{Limitations}

The use of NSPs as the primary site of participant recruitment may have created a sampling bias. Those PWID who participated in this study are more likely to be known to services and may represent the more chronic end of the addiction spectrum. The method of participant recruitment may have missed out on casual users and those who were newer to injecting drug use. Additionally, those who declined to participate may differ from those who did participate and we are unable to assess the degree to which our participants were representative of the broader NSP client group; however, a response rate of $71 \%$ is acceptable and suggests the sample is satisfactorily representative.
Symptoms of depression and anxiety were measured using self-report screening tools rather than a formal psychiatric diagnosis. The selection of the optimal tool for evaluating comorbid psychiatric conditions in drug using populations remains controversial. In our study, it is not possible to differentiate between psychiatric symptoms that are independent of substance use and those that were a consequence of it. Furthermore, the high level of psychological distress among our study participants is not surprising given their significant socioeconomic stress, disconnection from family, and the stigma connected to illicit drug addiction. Jacobs [66] argues that symptom checklists, as used in this study, take little regard of context, stress and coping, and that separating human distress from depression is difficult. The proportion of the participants who would reach a formal diagnosis is unknown, and many may be experiencing psychological distress related to their socially adverse circumstances and may not reach diagnostic criteria. Finally, we note that the use of a comparison group in our study design and doubleentry at the point of data entry would have strengthened the methods.

\section{Conclusions}

Our study into men who inject drugs in Delhi revealed an impoverished, vulnerable and isolated population whose lives are shaped by a significant level of psychosocial distress. The prevalence of depressive and anxiety symptoms among this population of men who inject drugs in Delhi was very high and suicidal thoughts and acts were disconcertingly common. Given the above and the high level of unmet need for mental health care in India, further research and discussion is required to inform the most appropriate public health response to the mental health and wellbeing needs of this population group.

\section{Competing interests}

The authors declare that they have no competing interests.

\section{Authors' contributions}

GA and MK designed the study and conceptualized the analysis in this paper. GA developed the sampling strategy and supervised the

implementation of data collection in collaboration with LS, SS and AM. AM entered and cleaned the data under the supervision of GA. GA undertook the data analysis and wrote the first draft of this paper. LS and SS provided links to the injecting drug user community and data collection sites, and contributed fundamentally important contextual knowledge that informed the development and implementation of the study. All authors read and contributed to the final manuscript.

\section{Acknowledgements}

The authors are thankful to Nossal Institute for Global Health (University of Melbourne) for funding this study. The authors acknowledge the skilled contribution of all the research staff and data collectors involved in implementing this study. Finally, we thank the participants for their willingness to share very personal information about their lives and their mental health. 


\section{Author details}

${ }^{1}$ Nossal Institute for Global Health, University of Melbourne, Victoria, Australia. ${ }^{2}$ The Society for Service to Urban Poverty (SHARAN), Delhi, India. ${ }^{3}$ Population Mental Health Group, Melbourne School of Population Health, University of Melbourne, Victoria, Australia.

Received: 2 January 2013 Accepted: 21 May 2013

Published: 27 May 2013

\section{References}

1. Prince M, Patel V, Saxena S, Maj M, Maselko J, Phillips MR, Rahman A: No health without mental health. Lancet 2007, 370:859-877.

2. Moussavi S, Chatterii S, Verdes E, Tandon A, Patel V, Ustun B: Depression chronic diseases, and decrements in health: results from the World Health Surveys. Lancet 2007, 370:851-858.

3. Patel V, Kleinman A: Poverty and common mental disorders in developing countries. Bull World Health Organ 2003, 81:609-615.

4. Bruckner TA, Scheffler RM, Shen G, Yoon J, Chisholm D, Morris J, Fulton BD, Dal Poz MR, Saxena S: The mental health workforce gap in low- and middle-income countries: a needs-based approach. Bull World Health Organ 2010, 89:184-194.

5. Wang PS, Aguilar-Gaxiola S, Alonso J, Angermeyer MC, Borges G, Bromet EJ, Bruffaerts R, De Girolamo G, De Graaf R, Gureje O, et al: Use of mental health services for anxiety, mood, and substance disorders in 17 countries in the WHO world mental health surveys. Lancet 2007, 370:841-850.

6. Patel V, Maj M, Flisher AJ MJDES, Koschorke M, Prince M: Reducing the treatment gap for mental disorders: a WPA survey. World Psychiatry, 9:169-176.

7. Patel V, Copeland J: The great push for mental health: why it matters for India. Indian J Med Res 2011, 134:407-409.

8. Khandelwal SK, Jhingan HP, Ramesh S, Gupta RK, Srivastava VK: India mental health country profile. Int Rev Psychiatry 2004, 16:126-141.

9. Bromet E, Andrade LH, Hwang I, Sampson NA, Alonso J, De Girolamo G, De Graaf R, Demyttenaere K, Hu C, Iwata N, et al: Cross-national epidemiology of DSM-IV major depressive episode. BMC Med 2011, 9:90.

10. Math SB, Srinivasaraju R: Indian Psychiatric epidemiological studies: Learning from the past. Indian journal of psychiatry 2010, 52:S95-S103.

11. Prasad J, Abraham VJ, Minz S, Abraham S, Joseph A, Muliyil JP, George K, Jacob KS: Rates and factors associated with suicide in Kaniyambadi Block, Tamil Nadu, South India, 2000-2002. Int I Soc Psychiatry 2006, 52:65-71.

12. Joseph A, Abraham S, Muliyil JP, George K, Prasad J, Minz S, Abraham VJ, Jacob KS: Evaluation of suicide rates in rural India using verbal autopsies, 1994-9. BMJ 2003, 326:1121-1122.

13. Aaron R, Joseph A, Abraham S, Muliyil J, George K, Prasad J, Minz S, Abraham VJ, Bose A: Suicides in young people in rural southern India. Lancet 2004, 363:1117-1118.

14. Abraham VJ, Abraham S, Jacob KS: Suicide in the elderly in Kaniyambadi block, Tamil Nadu, South India. Int J Geriatr Psychiatry 2005, 20:953-955.

15. Vijaykumar L: Suicide and its prevention: The urgent need in India. Indian J Psychiatry 2007, 49:81-84.

16. Crawford V, Crome IB, Clancy C: Co-existing problems of mental health and substance misuse (dual diagnosis): a literature review. Drugs Educ Prev Pol 2003, 10:S1-S74.

17. Kessler RC: The epidemiology of dual diagnosis. Biol Psychiatry 2004, 56:730-737.

18. Conner KR, Pinquart M, Duberstein PR: Meta-analysis of depression and substance use and impairment among intravenous drug users (IDUs). Addiction 2008, 103:524-534

19. Bakken K, Landheim AS, Vaglum P: Primary and secondary substance misusers: do they differ in substance-induced and substanceindependent mental disorders? Alcohol Alcohol 2003, 38:54-59.

20. Carroll KM, Power ME, Bryant K, Rounsaville BJ: One-year follow-up status of treatment-seeking cocaine abusers. Psychopathology and dependence severity as predictors of outcome. The J Nerv Ment Dis 1993, 181:71-79.

21. Rounsaville BJ, Kosten TR, Weissman MM, Kleber HD: Prognostic significance of psychopathology in treated opiate addicts. A 2.5-year follow-up study. Arch Gen Psychiatry 1986, 43:739-745.

22. Lemstra M, Rogers $M$, Thompson A, Moraros J, Buckingham R: Risk Indicators of Depressive Symptomatology Among Injection Drug Users and Increased HIV Risk Behaviour. Indicateurs de risque de symptomatologie dépressive et de comportement à risque accru du VIH chez les utilisateurs de drogues par injection 2011, 56:358-366.

23. Perdue $T$, Hagan $H$, Thiede $H$, Valleroy L: Depression and HIV risk behavior among Seattle-area injection drug users and young men who have sex with men. AIDS Education And Prevention: Official Publication of The International Society For AIDS Education 2003, 15:81-92.

24. Brienza RS, Stein MD, Chen M-H, Gogineni A, Sobota M, Maksad J, Hu P, Clarke J: Depression among needle exchange program and methadone maintenance clients. J Subst Abuse Treat 2000, 18:331-337.

25. Reyes J, Robles R, Colón H, Marrero C, Matos T, Calderón J, Shepard E: Severe Anxiety Symptomatology and HIV Risk Behavior Among Hispanic Injection Drug Users in Puerto Rico. AIDS Behav 2007, 11:145-150.

26. Havens JR, Sherman SG, Sapun M, Strathdee SA: Prevalence and Correlates of Suicidal Ideation Among Young Injection vs. Noninjection Drug Users. Subst Use Misuse 2006, 41:245-254.

27. Iskandar S, Kamal R, De Jong CA: Psychiatric comorbidity in injecting drug users in Asia and Africa. Curr Opin Psychiatry 2012, 25:213-218.

28. Gu J, Lau JTF, Chen H, Chen X, Liu C, Liu J: Mental health and interpersonal factors associated with HIV-related risk behaviors among non-institutionalized female injection drug users who are also sex workers in China. Women Health 2010, 50:20-36.

29. Liao Y, Tang J, Liu T, Chen X, Liu X, Hao W: A Pilot Study of Life Events and Mood Disorders: Self-Report Survey in Chinese Heroin-Dependent Individuals. Am J Addict 2011, 20:337-342.

30. Chen VC-H, Lin T-Y, Lee CT-C, Lai T-J, Chen H, Ferri CP, Gossop M: Suicide attempts prior to starting methadone maintenance treatment in Taiwan. Drug Alcohol Depend 2010, 109:139-143.

31. Sarin E, Samson L, Sweat M, Beyrer C: Human rights abuses and suicidal ideation among male injecting drug users in Delhi, India. Int I Drug Policy 2011, 22:161-166.

32. Aceijas C, Friedman SR, Cooper HL, Wiessing L, Stimson GV, Hickman M: Estimates of injecting drug users at the national and local level in developing and transitional countries, and gender and age distribution. Sex Transm Infect 2006, 82(Suppl 3):iii 0-iii17.

33. Priya KM, Singh S, Dorabjee J, Varma S, Samson L: How effective are Harm Reduction Programmes for Drug Users? Some Insights from an Evaluation of the Programme at Sharan in Delhi. J Heal Manag 2005, 7:219-236.

34. National AIDS Control Organisation: Annual Report 2011-12, pg 8. New Delhi: National AIDS Control Organisation; 2012.

35. Magnani R, Sabin K, Saidel T, Heckathorn D: Review of sampling hard-to-reach and hidden populations for HIV surveillance. AIDS 2005, 19(Suppl 2):S67-S72.

36. Karon JM, Wejnert C: Statistical methods for the analysis of time-location sampling data. J Urban Health 2012, 89:565-586.

37. Cai WD, Zhao J, Zhao JK, Raymond HF, Feng YJ, Liu J, McFarland W, Gan YX, Yang ZR, Zhang Y, et al: HIV prevalence and related risk factors among male sex workers in Shenzhen, China: results from a time-location sampling survey. Sex Transm Infect 2010, 86:15-20.

38. Ferreira LO, De Oliveira ES, Raymond HF, Chen SY, McFarland W: Use of time-location sampling for systematic behavioral surveillance of truck drivers in Brazil. AIDS Behav 2008, 12:S32-S38.

39. Sarin E, Kerrigan D: The impact of human rights violations and perceptions of discrimination on health service utilization among injection drug users in Delhi, India. Subst Use Misuse 2012, 47:230-243.

40. Indian Council of Medical Research, FHI 360: Integrated Behavioural and Biological Assessment (IBBA), Round 2 (2009-2010), National Summary Report. New Delhi: Indian Council of Medical Research \& FHI 360; 2011.

41. Szabo S: The World Health Organisation Quality of Life (WHOQOL) Assessment Instrument. In Quality of Life and Pharmaeconomics in Clinical Trials. 2nd edition. Edited by Spilker B. Philadelphia, New York: LippincottRaven Publishers; 1996

42. Hubley AM, Palepu A: Injection Drug User Quality of Life Scale (IDUQOL): findings from a content validation study. Health Qual Life Outcomes 2007, 5:46.

43. Hubley AM, Russell LB, Palepu A: Injection Drug Use Quality of Life scale (IDUQOL): a validation study. Health Qual Life Outcomes 2005, 3:43.

44. Kroenke K, Spitzer RL, Williams JBW: The PHQ-9: a new depression diagnostic and severity measure. Psychiatr Ann 2002, 32:509-521.

45. Kroenke K, Spitzer RL, Williams JB: The PHQ-9: validity of a brief depression severity measure. J Gen Intern Med 2001, 16:606-613. 
46. Lowe B, Spitzer RL, Grafe K, Kroenke K, Quenter A, Zipfel S, Buchholz C, Witte S, Herzog W: Comparative validity of three screening questionnaires for DSM-IV depressive disorders and physicians' diagnoses. J Affect Disord 2004, 78:131-140.

47. Martin A, Rief W, Klaiberg A, Braehler E: Validity of the Brief Patient Health Questionnaire Mood Scale (PHQ-9) in the general population. Gen Hosp Psychiatry 2006, 28:71-77.

48. Patel V, Araya R, Chowdhary N, King M, Kirkwood B, Nayak S, Simon G, Weiss HA: Detecting common mental disorders in primary care in India: a comparison of five screening questionnaires. Psychol Med 2008, 38:221-228.

49. Poongothai S, Pradeepa R, Ganesan A, Mohan V: Reliability and validity of a modified $\mathrm{PHQ}-9$ item inventory (PHQ-12) as a screening instrument for assessing depression in Asian Indians (CURES-65). J Assoc Physicians India 2009, 57:147-152.

50. Salve H, Goswami K, Nongkynrih B, Sagar R, Sreenivas V: Prevalence of psychiatric morbidity at Mobile Health Clinic in an urban community in North India. Gen Hosp Psychiatry 2012, 34:121-126.

51. Poongothai S, Pradeepa R, Ganesan A, Mohan V: Prevalence of depression in a large urban South Indian population-the Chennai Urban Rural Epidemiology Study (CURES-70). PLoS One 2009, 4:e7185.

52. Sidana S, Kishore J, Ghosh V, Gulati D, Jiloha R, Anand T: Prevalence of depression in students of a medical college in New Delhi: A crosssectional study. Australas Med J 2012, 5:247-250.

53. Hides L, Lubman DI, Devlin H, Cotton S, Aitken C, Gibbie T, Hellard M: Reliability and validity of the Kessler 10 and Patient Health Questionnaire among injecting drug users. Aust N Z J Psychiatry 2007, 41:166-168.

54. Kroenke K, Spitzer RL, Williams JB, Monahan PO, Lowe B: Anxiety disorders in primary care: prevalence, impairment, comorbidity, and detection. Ann Intern Med 2007, 146:317-325.

55. Osman A, Bagge CL, Gutierrez PM, Konick LC, Kopper BA, Barrios FX: The Suicidal Behaviors Questionnaire-Revised (SBQ-R): validation with clinical and nonclinical samples. Assessment 2001, 8:443-454.

56. Raymond HF, Ick T, Grasso M, Vaudrey J, McFarland W: Resource Guide: Time Location Sampling. San Francisco: San Francisco Department of Public Health, HIV Epidemiology Section; 2007.

57. Dupont VDN: The Dream of Delhi as a Global City. Int J Urban Regional 2011, 35:533-554

58. Government of India: Ministry of Home Affairs: Census of India. Delhi: Officer of the Registrar General \& Census Commissioner; 2011.

59. Mullatti L: Families in India: Beliefs and Realities. J Comp Fam Stud 1995, 26:11-25.

60. Latkin C, Srikrishnan AK, Yang C, Johnson S, Solomon SS, Kumar S, Celentano DD, Solomon S: The relationship between drug use stigma and HIV injection risk behaviors among injection drug users in Chennai, India. Drug Alcohol Depend 2010, 110:221-227.

61. Jorm AF: Mental health literacy. Public knowledge and beliefs about mental disorders. Br J Psychiatry 2000, 177:396-401.

62. Armstrong G, Kermode M, Raja S, Suja S, Chandra P, Jorm AF: A mental health training program for community health workers in India: impact on knowledge and attitudes. Int J Ment Heal Syst 2011, 5:17.

63. Colucci E, Kelly CM, Minas H, Jorm AF, Chatterjee S: Mental Health First Aid guidelines for helping a suicidal person: a Delphi consensus study in India. Int J Ment Heal Syst, 4:4.

64. Kingston AH, Morgan AJ, Jorm AF, Hall K, Hart LM, Kelly CM, Lubman DI: Helping someone with problem drug use: a Delphi consensus study of consumers, carers, and clinicians. BMC Psychiatry 2011, 11:3.

65. Heath I: Commentary: there must be limits to the medicalisation of human distress. BMJ 1999, 318:439-440.

66. Jacob KS: Depression: a major public health problem in need of a multisectoral response. Indian J Med Res 2012, 136:537-539.

67. World Health Organization: Promoting Mental Health: Concepts, Emerging Evidence, Practice. Geneva: World Health Organization; 2005.

doi:10.1186/1471-244X-13-151

Cite this article as: Armstrong et al:: Quality of life, depression, anxiety and suicidal ideation among men who inject drugs in Delhi, India. BMC Psychiatry 2013 13:151.

\section{Submit your next manuscript to BioMed Central and take full advantage of:}

- Convenient online submission

- Thorough peer review

- No space constraints or color figure charges

- Immediate publication on acceptance

- Inclusion in PubMed, CAS, Scopus and Google Scholar

- Research which is freely available for redistribution

Submit your manuscript at www.biomedcentral.com/submit
C BioMed Central 